\title{
Commentary \\ Nitric oxide inhibition rapidly increases blood pressure with no change in outcome in cardiogenic shock: the TRIUMPH trial
}

\author{
Réda Salem ${ }^{1}$ and Alexandre Mebazaa ${ }^{2}$
}

1'Département de Cardiologie, Centre Hospitalier de l'université de Montréal, 3840 rue Saint-Urbain Montréal (Québec)H2W 1T8, Canada
2Département d'Anesthésie-Réanimation, Hôpital Lariboisiere, AP-HP, Université Paris 7 Diderot Paris, 2 Rue A Paré, 75475 Paris Cedex 10 , France

Corresponding author: Alexandre Mebazaa, alexandre.mebazaa@lrb.aphp.fr

Published: 7 June 2007

This article is online at http://ccforum.com/content/11/3/136

(c) 2007 BioMed Central Ltd
Critical Care 2007, 11:136 (doi:10.1186/cc5925)

In the SHOCK trial, many patients had evidence, at shock onset, of systemic inflammatory response syndrome with fever, leukocytosis and decreased systemic vascular resistance confirming the classic notion that CS leads to a compensatory vasoconstriction [6-8]. This inappropriate systemic vasodilatation might be related to NO overproduction that can contribute to a vicious cycle of aggravation of CS. Inhibition of NO synthase (NOS) was theoretically appealing, targeting a new pathophysiological approach of $\mathrm{CS}$ in Ml.

The TRIUMPH study was a prospective, international, multicenter, randomized, double-blind, placebo-controlled trial testing the hypothesis that tilarginine (a non-specific inhibitor of NOS), when compared with placebo, would reduce 30-day mortality by $25 \%$ in patients with $\mathrm{Ml}$ complicated by refractory CS despite successful revascularization of the infarct-related artery [1]. Patients received a $1.0 \mathrm{mg} / \mathrm{kg}$ intravenous bolus of the drug followed by 5 hours of intravenous infusion of the drug at $1.0 \mathrm{mg} / \mathrm{kg}$ per hour or of a matching placebo.

shock (CS), namely the TRIUMPH trial, were recently published in Journal of the American Medical Association [1]. About 6 to $9 \%$ of myocardial infarctions (Mls), mostly with ST elevation, is complicated by CS, which is the leading cause of death. The SHOCK trial has shown the benefit of early revascularization in decreasing the rate of death, although the in-hospital and long-term mortality remains high $[2,3]$.

As long ago as 1939, $\mathrm{Ml}$ was shown to be associated with an inflammatory process, when Mallory and White described the time-related appearance of infiltrating cells [4]. Later, it was also reported that after being activated in vivo, macrophage cytotoxicity was mediating an L-arginine-dependent biochemical pathway that synthesized L-citrulline and nitric oxide (NO) [5]. The latter was identified as the effector molecule for macrophage cytotoxicity. NO is also a powerful vasodilator that may alter cardiac contractile function, with a positive inotropic effect at low level and negative at higher levels.
The major outcome was 30-day all-causes overall mortality, and stratification by age (less than 75 years or 75 years and over) was performed. The secondary outcome included duration and resolution of shock, New York Heart Association functional class at day 30 , and 6-month mortality.

The study was planned to include 658 treated patients in 130 centers for $90 \%$ power of detecting a $25 \%$ decrease in mortality. Finally, the study stopped enrolment after 398 patients on the basis of interim efficacy and futility analyses planned at $50 \%$ and $75 \%$ of enrolment.

Although tilarginine increased systolic blood pressure by $5 \mathrm{mmHg}(7 \mathrm{mmHg}$ versus $12 \mathrm{mmHg} ; p=0.01)$ at 2 hours, no effect on mortality was observed at 30 days. There was also

$\mathrm{CS}=$ cardiogenic shock $\mathrm{MI}=$ myocardial infarction; NOS = NO synthase. 
no difference in secondary outcomes such as resolution or duration of the CS, New York Heart Association functional class and 6-month mortality. There was, however, a 6\% absolute increase in 30-day mortality in the tilarginine group ( $48 \%$, versus $42 \%$ in the placebo) that was qualified by Ndrepepa and colleagues in their editorial in the same issue of JAMA as a disturbing event if this difference did not reach statistical significance $(p=0.24)$ [9]. We can reasonably wonder whether this difference would have been significant if the total planned enrolment had been reached. It is noteworthy that Dzavic and colleagues recently published a study assessing the effect of the inhibition of NOS on hemodynamics in patients with persistent CS after MI despite successful revascularization [10]. As opposed to the TRIUMPH study, this study, which used a bolus and 5-hour infusions of $N^{G}$-monomethyl-L-arginine $(0.15,0.5,1.0$ or $1.5 \mathrm{mg} / \mathrm{kg}$ per hour) compared with placebo, did not increase the mean arterial pressure at 2 hours (primary outcome). Another international randomized placebo-controlled trial of $N^{G}$-monomethyl-L-arginine hydrochloride at a dose ranging from 0.5 to $20 \mathrm{mg} / \mathrm{kg}$ per hour for 7 or 14 days for septic shock was also stopped prematurely because of an increased 28 -day mortality (59\% versus $49 \% ; p<0.001)$ [11].

All these randomized studies are disappointing because hope for a new therapeutic approach to CS had been raised by human pilot studies. Cotter and colleagues reported that inhibition of the NO pathway reduces 30-day mortality from $67 \%$ to $27 \%$ in a small randomized study (not placebocontrolled), with increased blood pressure and urine output [12]; this was the basis for the drug dosage and treatment duration for the TRIUMPH study. This again proves that a placebo-controlled double-blind study remains mandatory for evaluating new treatment modalities and is what evidencebased medicine is all about. Furthermore, the tilarginineinduced increase in systolic blood pressure leads to questions about the use of systolic blood pressure as a surrogate endpoint to predict outcome in CS.

Overall, treatments targeting the inflammatory cascade, especially the inhibition of the NO pathway, remain as deceiving in $\mathrm{Ml}$ as in sepsis. This might be related to the use of a non-specific inhibitor of NOS. More importantly, our group showed recently that, in patients with various degrees of sepsis and inflammation, NO overproduction leads to the very early production of peroxynitrite, which irreversibly inactivates proteins (including contractile proteins), suggesting that inhibiting the NO pathway probably comes too late and cannot restore an already impaired contractile function [13]. The TRIUMPH study gave strong indications for stopping any further trial with non-specific NOS inhibitors in CS and possibly also in all other cardiovascular diseases.

A better understanding of the physiopathology of the production of tissue-specific and systemic biomarkers is needed to develop new agents that have the potential to be effective in Ml-induced
CS. While we wait for new treatment modalities, the prevention of CS with early acute MI primary angioplasty remains the gold standard. Percutaneous left-ventricle-assisting devices may serve as a bridge to recovery or final treatment, namely transplantation.

\section{Competing interests}

The authors declare that they have no competing interests.

\section{References}

1. Alexander $\mathrm{JH}$, Reynolds HR, Stebbins AL, Dzavik V, Harrington RA, Van de Werf F, Hochman JS: Effect of tilarginine acetate in patients with acute myocardial infarction and cardiogenic shock: the TRIUMPH randomized controlled trial. JAMA 2007, 297:1657-1666.

2. Goldberg RJ, Samad NA, Yarzebski J, Gurwitz J, Bigelow C, Gore JM: Temporal trends in cardiogenic shock complicating acute myocardial infarction. $N$ Engl J Med 1999, 340:1162-1168.

3. Hochman JS, Sleeper LA, Webb JG, Sanborn TA, White HD, Talley JD, Buller CE, Jacobs AK, Slater JN, Col J, et al.; SHOCK Investigators: Early revascularization in acute myocardial infarction complicated by cardiogenic shock. $N$ Engl J Med 1999, 341:625-634.

4. Mallory GK, White PD: The speed of healing of myocardial infarction. Am Heart J 1939, 18:647-671.

5. Wildhirt AM, Dudek RR, Suzuki H, Bing RJ: Involvement of inducible nitric oxide synthase in the inflammatory process of myocardial infarction. Int J Cardiol 1995, 50:253-261.

6. Hochmann JS: Cardiogenic shock complicating myocardial infarction: expanding the paradigm. Circulation 2003, 107: 2998-3002.

7. Frangogiannis FG, Smith CW, Entman ML: The inflammatory response in myocardial infarction. Cardiovasc Res 2002, 53: 31-47.

8. Kohsaka S, Menon V, Lowe AM, Lange M, Dzavik V, Sleeper LA, Hochmann JS, SHOCK Investigators: Systemic response syndrome after acute myocardial infarction complicated by cardiogenic shock. Arch Intern Med 2005, 165:1643-1650.

9. Ndrepepa G, Schomig A, Kastrati A: Lack of benefit from nitric oxide synthase inhibition in patients with cardiogenic shock: looking for the reasons. JAMA 2007, 297:1711-1713.

10. Dzavik V, Cotter G, Reynolds HR, Alexander JH, Ramanathan K, Stebbins AL, Hathaway D, Farkouh ME, Ohman EM, Baran DA, et al.: Effect of nitric oxide synthase inhibition on haemodynamics and outcome of patients with persistent cardiogenic shock complicating acute myocardial infarction: a phase II doseranging study. Eur Heart J 2007, 28:1109-1116.

11. López A, Lorente JA, Steingrub J, Bakker J, McLuckie A, Willatts S, Brockway M, Anzueto A, Holzapfel L, Breen D, et al:: Multiplecenter, randomized, placebo-controlled, double-blind study of the nitric oxide synthase inhibitor 546C88: effect on survival in patients with septic shock. Crit Care Med 2004, 32:21-30.

12. Cotter G, Kaluskia E, Milo O, Blatt A, Salah A, Hendler A, Krakover R, Golick A, Vered Z: LINCS: L-NAME (a NO synthase inhibitor) in the treatment of refractory cardiogenic shock. A prospective randomized study. Eur Heart J 2003, 24:12871295.

13. Rabuel C, Mebazaa A: Septic shock: a heart story since the 60's. Intensive Care Med 2006, 32:799-807. 